\title{
O ESTADO COMO TOTALIDADE. ALGUMAS NOTAS A PARTIR DE GRUNDLINIEN DER PHILOSOPHIE DES RECHTS
}

\section{THE STATE AS TOTALITY. SOME NOTES FROM GRUNDLINIEN DER PHILOSOPHIE DES RECHTS}

\author{
Sara Sofia Lúcio Vargas*
}

\begin{abstract}
RESUMO
O presente artigo procura contribuir para o debate em torno de uma certa noção de Estado e de uma certa relação com o indivíduo que a acompanha. Fá-lo-emos na esteira de Georg Wilhelm Friedrich Hegel, essencialmente a partir do seu Princípios da Filosofia do Direito (Grundlinien der Philosophie des Rechts, 1821), percorrendo, em algumas notas, o que aí é entendido como Estado e como competência do indivíduo.
\end{abstract}

PALAVRAS-CHAVE: Hegel. Indivíduo. Família. Sociedade civil. Estado.

\begin{abstract}
This paper seeks to contribute to the debate around a certain notion of State and a certain relationship with the individual that accompanies it. We do so in the wake of Georg Wilhelm Friedrich Hegel, essentially from his Elements of the Philosophy of Right (Grundlinien der Philosophie des Rechts, 1821), covering in some notes, which here is understood as a State and as a competence of individual.

KEYWORDS: Hegel. Individual. Family. Civil society. State.
\end{abstract}

\footnotetext{
* Mestre em Ensino da Filosofia no Ensino Secundário pela Universidade de Lisboa. Doutoranda em Filosofia Política na Faculdade de Letras da Universidade de Lisboa. E-mail: svargas@ @ampus.ul.pt.
} 


\section{Nótula introdutória}

O artigo que trazemos à liça procura contribuir para o debate em torno de uma certa noção de Estado e de uma certa relação com o indivíduo que a acompanha. Fá-lo-emos na esteira de Georg Wilhelm Friedrich Hegel (1770-1831), essencialmente a partir do seu Princípios da Filosofia do Direito (Grundlinien der Philosophie des Rechts, 1821), percorrendo, em algumas notas, o que aí é entendido como Estado e como competência do indivíduo.

Entendemos que se trata de um debate pertinente face ao desenvolvimento que o Estado-nação tem tido desde a sua "primavera", mormente se levarmos em conta que este já não é o que era, e que se encaminha para outros sentidos que não os mais correspondentes aos seus primevos anseios e necessidades (HABERMAS, 1999, pp.281-294).

Não obstante, o presente artigo não visa estabelecer uma correspondência direta com os nossos dias, tão-pouco uma apologia das teses hegelianas. Antes, ancora-se na firme convicção de que não devemos ir para lado algum sem saber muito bem de onde viemos.

\section{Delineamento geral da moralidade objetiva}

O indivíduo possui uma vontade livre (freien Willen) (cf. HEGEL, 1970b, §34), mas esta ainda não será suficiente para compreender o seu lugar na realidade. Ora, o indivíduo atua em relação, contextualizado num mundo de relações. É nestas relações, rigorosamente em sentido conflituoso, que os indivíduos afirmam a sua vontade. Este é o momento de “transição do direito para a moralidade subjetiva” (cf. HEGEL, 1970b, §103).

Tal acontece porque "a vontade subjetiva, como sendo imediatamente para si e distinta do em si, é pois abstrata, limitada e formal” (HEGEL, 1997, §108, pp.98-99) ${ }^{1}$. É por isso que as relações entre indivíduos remetem-nos de uma moralidade subjetiva (Moralität) para uma moralidade objetiva (Sittlichkeit ${ }^{2}$ ),

O Bem, que é a substância universal da liberdade mas ainda uma forma abstrata, apela para determinações e para um princípio de tais determinações que lhe seja idêntico, ao passo que, reciprocamente, a consciência moral, que é princípio de

\footnotetext{
1 "Der subjektive Wille als unmittelbar für sich und von dem an sich seienden unterschieden ist daher abstrakt, beschränkt und formell.” (HEGEL, 1970b, §108, p.206).

${ }^{2}$ Note-se que o mesmo termo poderia ser traduzido por "eticidade", porém optámos por seguir a tradução de Orlando Vitorino pela qual nos guiamos, mantendo "moralidade objetiva".
} 
determinação mas apenas abstrato, apela para a universalidade e para a objetividade. Estes dois termos, cada um deles por si elevado à totalidade, revelam-se como indefinidos e devem ser determinados. Ora, a integração destas duas totalidades relativas na identidade absoluta está já em si mesma efetuada precisamente quando a certeza subjetiva de si, ao desvanecer-se no vazio, se torna idêntica à universalidade abstrata do Bem. A identidade, agora concreta, do bem e da vontade subjetiva, a sua verdade, é a moralidade objetiva (HEGEL, § 141, 1997, pp.138-139) ${ }^{3}$.

É nesta dimensão ética onde o indivíduo se depara com a dimensão cultural e se inserem precisamente os diferentes níveis de relação entre os indivíduos: família (Familie), sociedade civil (bürgerliche Gesellschaft ${ }^{4}$ ) e Estado (Staat), de acordo com Hegel.

Por mais que se tente isolar, que se tente "esconder" nas profundezas de uma solidão, o indivíduo jamais vive sozinho - ele vive sempre no mundo (de relações). Esta é a condição do seu existir - o ser humano mantém sempre uma relação com o outro, um outro que lhe é exterior.

Neste sentido, o ser humano é um ser de relação, ele nasce no seio de uma família na qual estabelece os primeiros vínculos relacionais, mas esta família está já inserida numa comunidade, numa sociedade civil, enquadrada, em primeira instância, em algo mais abrangente - num Estado.

A ordem de perceção que o indivíduo tem das suas relações não é a ordem lógica da sua inserção nelas. Ele tem primeiro uma noção do particular, é certo, para chegar ao universal. Mas, como o autor argumentava, o universal é anterior ao particular, que é a sua parte. Por isto se pode deduzir, então, que o Estado é anterior a cada indivíduo e a cada família, não se tratando de uma anterioridade temporal (cf. HEGEL, 1970b, §§ 265-269).

A moralidade objetiva em Hegel caracteriza-se pela efetivação da Liberdade no real. Se se reparar, a título de exemplo, na divisão da vontade livre que Hegel elaborou posteriormente na Enciclopédia das Ciências Filosóficas em Epítome (Enzyklopãdie der Philosophischen Wissenschaften, 1830), vê-se que esta é:

\footnotetext{
3 "Für das Gute, als das substantielle Allgemeine der Freiheit, aber noch Abstrakte, sind daher ebensosehr Bestimmungen überhaupt und das Prinzip derselben, aber als mit ihm identisch, gefordert, wie für das Gewissen das nur abstrakte Prinzip des Bestimmens, die Allgemeinheit und Objektivität seiner Bestimmungen gefordert ist. Beide, jedes so für sich zur Totalität gesteigert, werden zum Bestimmungslosen, das bestimmt sein soll. - Aber die Integration beider relativen Totalitäten zur absoluten Identität ist schon an sich vollbracht, indem ebendiese für sich in ihrer Eitelkeit verschwebende Subjektivität der reinen Gewißheit seiner selbst identisch ist mit der abstrakten Allgemeinheit des Guten; -die somit konkrete Identiät des Guten und des subjektiven Willens, die Wahrheit derselben, ist die Sittlichkeit." (HEGEL, 1970b, § 141, p.286).

${ }^{4}$ Aqui o mesmo termo poderia ser traduzido por "sociedade civil burguesa", no entanto também preferimos manter tal como vem na tradução de Orlando Vitorino - "sociedade civil", mantendo a coerência das passagens utilizadas.
} 
A. Em primeiro lugar, imediata e, por isso, singular - a pessoa; a existência que esta dá à sua liberdade é a propriedade. O direito como tal é o direito formal, abstrato; B. Reflexa em si, de modo que tem a sua existência dentro de si e é assim simultaneamente determinada como particular, como o direito da vontade subjetiva - a moralidade; C. A vontade substancial como a realidade efetiva conforme ao seu conceito no sujeito e totalidade da necessidade - a moralidade objetiva, na família, na sociedade civil e no Estado (1992, p. 106) ${ }^{5}$.

A vontade é instrumental para a realização da Liberdade e, para Hegel, só há Liberdade se a vontade livre tiver por conteúdo a Liberdade, ou seja, somente se a Liberdade se tiver tornado a realidade do mundo.

Poder-se-á dizer que a moralidade objetiva é a moralidade concreta como conjunto da moralidade da família, da sociedade civil e do Estado. A substância moral adotada não é o eu como pessoa tal como no "direito abstrato", nem o direito da consciência, mas, sim, "a substância moral, como o que contém a consciência refletida de si ligada ao seu conceito, é o espírito real de uma família e de um povo" (HEGEL, 1992, §156, p.148) ${ }^{6}$.

A moralidade objetiva, a fim de realizar a Liberdade, percorre, dialeticamente, três momentos, tal como todo o sistema filosófico hegeliano. São eles, já enunciados: família, como moralidade mais imediata e natural; sociedade civil, associação com o fim de atender às carências (Bedürfnisse) e dar garantia de proteção à propriedade privada (Privateigentum); e, Estado, como consagração universal da vida pública.

A família é a primeira unidade de união social. Hegel descreve, por exemplo, o reconhecimento do casamento como uma "união moral" (sittlichen Verbindung). A família tem a sua realização no casamento e o seu desfecho são os filhos como perpetuação da mesma (cf. HEGEL, 1970b, §§ 160-169). Como Eric Weil aponta, indo ao encontro do nosso autor: "[...] a família tem os seus fundamentos em parte na Natureza, no dado imediato da individualidade biológica e do acaso da afeção pessoal" (tradução própria) ${ }^{7}$. A sociedade civil é como um agrupamento de seres privados, preocupados com a realização das suas pretensões pessoais.

\footnotetext{
5 “A. selbst zunächst unmittelbar und daher als einzelner, - die Person; das Dasein, welches diese ihrer Freiheit gibt, ist das Eigentum. Das Recht als solches ist das formelle, abstrakte Recht; B. in sich reflektiert, so daß er sein Dasein innerhalb seiner hat und hierdurch zugleich als partikulärer bestimmt ist, das Recht des subjektiven Willens, - die Moralität; C. der substantielle Wille als die seinem Begriffe gemäße Wirklichkeit im Subjekte und Totalität der Notwendigkeit, - die Sittlichkeit, in Familie, bürgerlicher Gesellschaft und Staat." (HEGEL, 1970a, p.306).

Na tradução de Artur Morão constava "eticidade" no lugar de "moralidade objetiva", procedemos a esta alteração para manter a coerência em relação ao termo e à tradução adotados.

6 "Die sittliche Substanz, als das für sich seiende Selbstbewußtsein mit seinem Begriffe geeint enthaltend, ist der wirkliche Geist einer Familie und eines Volks." (HEGEL, 1970b, §156, p.305).

7 “[...] la famille, ayant ses fondements en partie dans la nature, dans le donné immédiat de individualité biologique et du hasard de l'affection personnelle" (WEIL, 1950, p. 44).
} 
Para Hegel, o Estado advém, de certo modo, da necessidade de objetivação do Espírito, que é a necessidade de objetivação histórica do Espírito. O Estado é, para o autor, a síntese suprema da família e da sociedade civil. É no Estado que se dá a realização efetiva da moralidade objetiva.

\section{A sociedade civil como "momento negativo"}

Hegel declara-nos uma organização sistemática da ação humana e das suas obras na História, que são as "objetivações” do Espírito. A ação humana articula-se nos três momentos da moralidade objetiva referidos. Considerando-a movida por interesses dirigidos à obtenção de algo, sem interesse não haveria ação. Isto caracteriza e diferencia a sociedade civil e o Estado.

De acordo com o autor, é a natureza particular ou geral do interesse que move os seres humanos à ação ou do bem que buscam por meio dela. Assim, as ações que provêm de um interesse particular dão origem à sociedade civil e nesta se inscrevem. Por outro lado, o Estado é produto de uma ação que obedece ao interesse geral de toda a coletividade, dirigindo-se ao bem universal (cf. HEGEL, 1970b, § 289 n).

Hegel denomina igualmente a sociedade civil de sistema de carências (Systems der Bedürfnisse), surgindo da dinâmica imposta pela satisfação das carências particulares. Assim, a ação que conduz das carências à sua satisfação gera um fluxo de vínculos recíprocos entre os indivíduos e cria um nível específico de interação e comunicação: a própria sociedade civil $^{8}$.

Neste contexto, impõe-se, para este filósofo, a necessidade individual, a questão da propriedade e do trabalho. Para ele, é graças à propriedade que o indivíduo se insere no corpo social e jurídico. Emerge, portanto, a propriedade como momento eminente do desenvolvimento do Espírito humano, pois a mesma destaca-se como porta de inserção dos

\footnotetext{
${ }^{8}$ De modo que a sociedade civil contém, segundo Hegel, três momentos: "A) a mediação da carência e a satisfação dos indivíduos pelo seu trabalho e a satisfação de todos os outros: é o sistema de carências (A questão da carência em Hegel é de dar conta do que é imediato pela particularidade.); B) a realidade do elemento universal de liberdade implícito neste sistema é a defesa da propriedade pela justiça; C) a preocupação contra o resquício de contingência destes sistemas e a defesa dos interesses particulares como algo de administração e pela corporação." (1992, § 188, p.173). "A. Die Vermittlung des Bedürfnisses und die Befriedigung des Einzelnen durch seine Arbeit und durch die Arbeit und Befriedigung der Bedürfnise aller Übrigen, - das System der Bedürfnisse. B. Die Wirklichkeit des darin enthaltenen Allgemeinen der Freiheit, der Schutz des Eigentums durch die Rechtspflege. C. Die Vorsorge gegen die in jenen Systemen zurückbleibende Zufälligkeit und die Besorgung des besonderen Interesses als eines Gemeinsamen, durch die Polizei und Korporation." (1970b, § 188, p.346).
} 
indivíduos na vida legal. A grande necessidade da propriedade é a necessidade da pessoa se objetivar (cf. HEGEL, 1970b, § 232) ${ }^{9}$.

A sociedade civil é o momento intermediário entre a família e o Estado, representando na moralidade objetiva o "momento negativo" que é a fase do desenvolvimento histórico em que ocorre a dissolução da unidade familiar. O primeiro princípio da sociedade civil é a pessoa concreta com as suas carências, buscando a satisfação destas pela via do trabalho; o seu segundo princípio é a universalidade que deriva do primeiro, pois a particularidade da satisfação das carências da pessoa entra em relação com outras particularidades, sendo esta a condição efetiva dos seus fins.

O indivíduo na sociedade civil não é ainda o homem racional, mas sim o homem do trabalho, em virtude das carências, como ser carente que produz e consome. Por isto, a sociedade mantém uma relação finita, de uma unidade externa e não interna entre os indivíduos. Cada indivíduo é tido como fim e isto é específico da esfera económica, pela qual diverge da esfera política.

No que respeita à dimensão política, o ser humano é portador de direitos universais. O sujeito do direito não é um homem natural, mas o homem do mundo da cultura que alcança o reconhecimento universal. A sociedade civil é o momento que antecede a realização da Razão e da Liberdade, isto é, o Estado.

A sociedade do Estado transcende a sociedade familiar, bem como transcende a sociedade civil, que é um conjunto de interesses económicos, não porque seja um instrumento superior em perfeição para a realização dos fins materiais e espirituais dos indivíduos, mas porque, segundo o próprio autor, tem ele mesmo uma realidade e um valor superior ao valor particular e privado das sociedades precedentes. Isto deve-se exatamente à maior universalidade do Estado, que é uma superior objetivação do Espírito, como espírito vivente, razão encarnada ou deus terreno.

O Estado é aqui o momento mais rico em determinações tendo, dialeticamente, uma realidade superior e, eticamente, um valor igualmente superior relativamente à família e à sociedade civil. Trata-se da realização enquanto "processo ativo de elevação a uma instância de superior concreção" (BARATA-MOURA, 1990, p. 113).

\footnotetext{
${ }^{9}$ Como brevemente aludido na passagem já citada da Enciclopédia das Ciências Filosóficas em Epítome.
} 


\section{O Estado como totalidade moral}

Nos Princípios da Filosofia do Direito, o Estado aparece como o fim da atividade da moralidade objetiva de uma comunidade, que une família e sociedade civil. O conceito de Estado não surge só e simplesmente como aparato institucional, mas como a forma que efetiva a realização social finita plenamente. O Estado é a totalidade (Totalität) moral, o terceiro momento da moralidade objetiva, como se referiu, sendo o universal que transcende a família e a sociedade civil. Estas são partes daquele e, como partes, estão inseridas nesse todo que é o Estado.

A moralidade objetiva é, para Hegel, a ideia de liberdade (Idee der Freiheit), como "conceito" (Begriff) e a sua "realização" (Verwirklichung) e "o Estado é a realidade em ato da Ideia moral objetiva, o espírito como vontade substancial revelada, clara para si mesma, que se conhece e se pensa, e realiza o que sabe e porque sabe" (HEGEL, 1992, § 257, p. 216) ${ }^{10}$.

$\mathrm{Na}$ terceira parte dos Princípios da Filosofia do Direito, o autor desenvolve o pensamento dessa mesma moralidade objetiva como a terceira esfera do direito. Ela é a realidade efetiva da liberdade e compreende os três momentos atrás descritos, e é no âmbito do Estado que se realiza efetivamente a liberdade (como mais adiante se voltará a abordar).

A já referida tripartição que Hegel faz da moralidade objetiva corresponde, como nos diz Manuel José do Carmo Ferreira na sua apresentação ao Prefácio ${ }^{11}$ de Princípios da Filosofia do Direito:

[...] à posição diferenciada da consciência da liberdade, ao processo da sua efetivação, o qual, partindo de uma abstração, a pessoa formalmente identificada como mero sujeito de relações jurídicas, passando pela autonomia da consciência individual, sujeito do dever moral, atinge no Estado a sua realidade efetiva, a vontade racional e livre realizada que suscita para si um mundo como extensão da sua liberdade, uma "segunda natureza", o complexo das instituições em que o espírito ganha objetividade, a vida organizada de um povo. (1990, p. 175)

É, pois, nos povos que o Espírito encarna, porque é neles, nas comunidades, que o Espírito se concretiza numa história universal (Weltgeschichte) ${ }^{12}$.

\footnotetext{
10 "Der Staat ist die Wirklichkeit der sittlichen Idee - der sittliche Geist, als der offenbare, sich selbst deutliche, substantielle Wille, der sich denkt und weiß und das, was er weiß und insofern er es weiß, vollführt." (HEGEL, 1970b, §257, p.398).

${ }^{11}$ Mais precisamente na edição do Prefácio publicada em separado em 1820, também conhecida como: Direito Natural e Ciência do Estado em Compêndio - linhas fundamentais da Filosofia do Direito (Naturrecht und Staatswissenschaft im Grundrisse - Grundlinien der Philosophie des Rechts), constante nas duas versões que estamos a usar.
} 
Hegel reconhece que o Estado precede a existência do indivíduo tomado na sua singularidade o que se assemelha ao que Aristóteles havia defendido:

[...] é evidente que a cidade [que pode ser lida contemporaneamente como o Estado] é [...] anterior ao indivíduo, porque se um indivíduo separado não é autossuficiente, permanecerá em relação à cidade [- Estado -] como as partes em relação ao todo. [...] a cidade é por natureza anterior à família e a cada um de nós, individualmente considerado; é que o todo é necessariamente anterior à parte. (1998, 1253 a, p.55)

Embora Hegel esteja ciente de que as instituições antecedem os indivíduos e estes só nelas se possam realizar, o autor considera que não é qualquer instituição que conduz à efetivação do indivíduo. No parágrafo 153 dos Princípios da Filosofia do Direito, o autor escreve que "o direito que os indivíduos têm de estar subjetivamente destinados à liberdade satisfaz-se quando eles pertencem a uma realidade moral objetiva" ${ }^{13}$. Essa realidade moral objetiva encontra-se no seio do Estado, é aí que está concretizada.

Ora, citando, na nota daquele parágrafo, a resposta conhecida à questão acerca da melhor maneira de educar um filho - "Faz dele cidadão de um Estado cujas ideias sejam boas" (HEGEL, 1992, § 153, p. 148 n.) ${ }^{14}$ - , Hegel evidencia aí o que defende: é que a realização da individualidade, que se pode entender como o exercício da liberdade, só pode encontrar o seu ponto de sustentação na totalidade moral, que é o próprio Estado:

\begin{abstract}
Quando se confunde o Estado com a sociedade civil, destinando-o à segurança e proteção da propriedade e da liberdade pessoais, o interesse dos indivíduos enquanto tais é o fim supremo para que se reúnem, do que resulta ser facultativo ser membro de um Estado. Ora, é muito diferente a sua relação com o indivíduo. Se o Estado é o espírito objetivo, então só como membro é que o indivíduo tem objetividade, verdade e moralidade (HEGEL, 1992, § 258, p. 217) ${ }^{15}$.
\end{abstract}

$12 \mathrm{O}$ que acaba por aludir de certa maneira a Johann Gottlieb Fichte (1762-1814), por exemplo, no seu VII Discurso à Nação refere que um povo é como um privilegiado recetor e transmissor de uma cultura, de uma ordem das coisas das quais deve ser portador (cf. FICHTE, 2009).

${ }^{13}$ Continua o autor: "Com efeito, é numa tal objetividade que reside a verdade da certeza da sua liberdade e na realidade moral possuem eles realmente a sua essência própria, a sua íntima universalidade.” (HEGEL, 1992, § 153, p. 148). "Das Recht der Individuen für ihre subjektive Bestimmung zur Freiheit hat darin, daß sie der sittlichen Wirklichkeit angehören, seine Erfüllung, indem die Gewißheit ihrer Freiheit in solcher Objektivität ihre Wahrheit hat und sie im Sittlichen ihr eigenes Wesen, ihre innere Allgemeinheit wirklich besitzen.", (HEGEL, 1970b, §153, p.303).

14 “[...] wenn du ihn zum Bürger eines Staats von guten Gesetzen machst.” (HEGEL, 1970b, §153, p.303 n.).

15 "Wenn der Staat mit der bürgerlichen Gesellschaft verwechselt und seine Bestimmung in die Sicherheit und den Schutz des Eigentums und der persönlichen Freiheit gesetzt wird, so ist das Interesse der Einzelnen als solcher der letzte Zweck, zu welchem sie vereinigt sind, und es folgt hieraus ebenso, daß es etwas Beliebiges ist, Mitglied des Staates zu sein. - Er hat aber ein ganz anderes Verhältnis zum Individuum; indem er objektiver Geist ist, so hat das Individuum selbst nur Objektivität, Wahrheit und Sittlichkeit, als es ein Glied desselben ist." (HEGEL, 1970b, § 258, 399). 


\section{A realização efetiva da Razão e da Liberdade}

Hegel aspirou ao estabelecimento do governo da razão, uma razão ampliada, na qual coubessem todas as obras da criação do espírito humano, como a Arte, a Religião, e a Filosofia, que são os três momentos da cultura, os sistemas políticos, na história. Como realçara na sua Fenomenologia do Espírito (Phänomenologie des Geistes, 1807) - o "saber absoluto" (Das absolute Wissen) (cf. HEGEL, 1970c, VI-VIII).

Para este filósofo, a Razão é o princípio, o processo e a modalidade de realização e o que é racional tem de acontecer, tal como aquilo que é é racional. Deste modo, a Razão não é somente o conjunto dos princípios e das regras segundo as quais pensamos o mundo, ela é igualmente a realidade profunda das coisas, a essência do próprio ser. A Razão não se circunscreve a um modo de pensar as coisas, é também o próprio modo de ser das coisas, assim referiu o autor, no seu Prefácio aos Princípios da Filosofia do Direito: “O que é racional é real, e o que é real é racional" (HEGEL, 1992, p.xxxvi) ${ }^{16}$.

Ora, sendo o Estado real, ele é racional. É isto que Hegel declara como objetivo: uma tentativa de conceber o Estado como algo de racional em si e, tendo em conta o já exposto neste artigo, o Estado como racional em si é também para realizar, para concretizar, porque a razão é essa modalidade de ser. Posto isto, o Estado não é um dever ser, mas um a fazer ${ }^{17}$. Há uma racionalidade e esta tem de se realizar no concreto (konkreteren) ${ }^{18}$. Tal realização no concreto dá-se precisamente no Estado, de modo que a razão tem de se realizar assim.

O Espírito na sua liberdade é a mais alta afirmação da Razão e da Liberdade, como figura de afirmação do Estado. É a forma superior da sua concretização numa história universal. De modo que, então, o Estado é a Razão que se realiza na História, logo a realização do próprio Espírito. É no Estado que o Espírito se objetiva e se concretiza, tornando-se efetivamente real.

\footnotetext{
16 "Was vernünftig ist, das ist wirklich; und was wirklich ist, das ist vernünftig." (HEGEL, 1970b, p.24).

${ }^{17}$ Neste sentido, Eric Weil, em Hegel et l'État, refere, acerca da liberdade, que esta é positiva em Hegel na medida em que é uma liberdade de fazer e não uma liberdade negativa de não fazer (cf. WEIL, 1950, p. 37).

18 "Isso é também o que constitui o sentido concreto do que já designamos, de maneira abstrata, como unidade da forma e do conteúdo. Com efeito, em sua mais concreta significação, a forma é a razão como conhecimento conceitual e o conteúdo é a razão como essência substancial da realidade moral e também natural. A identidade consciente do conteúdo e forma é a Ideia filosófica." (HEGEL, 1992, p.xxxviii). "Dies ist es auch, was den konkreteren Sinn dessen ausmacht, was oben abstrakter als Einheit der Form und des Inhalts bezeichnet worden ist, denn die Form in ihrer konkretesten Bedeutung ist die Vernunft als begreifendes Erkennen, und der Inhalt die Vernunft als das substantielle Wesen der sittlichen wie der natürlichen Wirklichkeit; die bewußte Identität von beidem ist die philosophische Idee." (HEGEL, 1970b, p.27).
} 
A essência do Espírito é, para Hegel, a Liberdade. Contudo, a Liberdade efetivamente real não é alguma coisa que esteja imediatamente no Espírito. Ela precisa da mediação da Razão. Outro ponto importante a frisar acerca da Liberdade neste autor é que esta não está desligada da necessidade: não é uma liberdade do livre-arbítrio, aliás ele critica esta liberdade (cf. HEGEL, 1970b, p.20).

Em Hegel não há contraste entre a Liberdade e a Necessidade. Não há uma liberdade da razão, mas antes uma liberdade para realizar a razão: a Liberdade é a realização necessária da própria Razão. Assim,

\begin{abstract}
O domínio do direito é o espírito em geral; aí, a sua base própria, o seu ponto de partida está na vontade livre, de tal modo que a liberdade constitui a sua substância e o seu destino e que o sistema do direito é o império da liberdade realizada, o mundo do espírito produzido como uma segunda natureza a partir de si mesmo (HEGEL, 1992, § 4, p.12) ${ }^{19}$.
\end{abstract}

Esta é a concretização do Espírito - a Liberdade. O Estado justifica-se, pois, como exercício da liberdade. “[O] Estado [é o] 'poder absoluto sobre a terra', designado como 'a realidade efetiva da Ideia', como 'realidade efetiva da liberdade concreta' ", assim nos diz Carmo Ferreira (1990, p. 180).

Se o Espírito se encarna no Estado e a essência do Espírito é a Liberdade, então a Liberdade realiza-se no Estado, quer dizer, este é a realização da Liberdade. Isto equivale a afirmar que é no Estado que a essência do Espírito se realiza. O Estado é, para Hegel, concretização da Liberdade e da Razão, de modo que é necessário realizar. O Estado é a objetivação do Espírito, a sua manifestação objetiva.

\title{
O Estado; onde se realiza a liberdade concreta
}

Tendo sido observado que a razão é a modalidade de ser das coisas, de que nada pode ser mais universal do que aquilo que está na raiz de tudo o resto, e está presente em todas elas enquanto reais, cabe agora concluir a noção de Estado que nos motivou o debate.

Jean Wahl referia a respeito de Hegel: "Tudo o que existe só existe pela sua relação com a totalidade e finalmente com a totalidade - acrescentando mais adiante, em acordo com Hegel

\footnotetext{
19 "Der Boden des Rechts ist überhaupt das Geistige und seine nähere Stelle und Ausgangspunkt der Wille, welcher frei ist, so daß die Freiheit seine Substanz und Bestimmung ausmacht und das Rechtssystem das Reich der verwirklichten Freiheit, die Welt des Geistes aus ihm selbst hervorgebracht, als eine zweite Natur, ist." (HEGEL, 1970b, § 4, p.46).
} 
-, estou profundamente unido ao Estado de que sou membro [...]"(WAHL, 1962, p. 23). Ora, o Estado é essa totalidade, o universal que engloba todos os particulares. O indivíduo é uma individualidade particular inserida num Estado, é membro, logo, parte, do universal que é o Estado.

Nesta perspetiva, segundo o autor alemão, o universal é logicamente anterior ao particular, neste sentido, a primazia do universal em relação ao individual é lógica, e não temporal.

De modo que, embora o indivíduo se dê conta primeiramente da sua existência, de ter uma família e da sociedade civil na qual se encontra, e só posteriormente ter a real noção de que tudo o que conhece está inserido num Estado, ele mesmo o está, não significa que o Estado seja posterior logicamente ao indivíduo. O Estado é o contexto que envolve o indivíduo, na verdade, que organiza a sua vida eticamente no espaço público e é quando o indivíduo se reconhece como seu membro que se reconhece plenamente, regressando a si, consciente do que é nesse universal.

O Estado é, pois, a totalidade onde o indivíduo se insere, onde as comunidades particulares, como a família, a sociedade civil, estão inseridas, o universal ao qual reconhecem estar submetidos e onde se realiza a liberdade concreta (konkrete Freiheit),

\begin{abstract}
Ora, a liberdade concreta consiste em a individualidade pessoal, com os seus particulares, de tal modo possuir o seu pleno desenvolvimento e o reconhecimento dos seus direitos para si (nos sistemas da família e da sociedade civil) que, em parte, consciente e voluntariamente o reconhecem como seu particular espírito substancial e para ele agem como seu último fim. Daí provém que nem o universal tem valor e é realizado sem o interesse, a consciência e a vontade particulares, nem os indivíduos vivem como pessoas privadas unicamente orientadas pelo interesse e sem relação com a vontade universal; deste fim são conscientes em sua atividade individual (HEGEL, 1992, §260, pp. 225-226) ${ }^{20}$.
\end{abstract}

O particular, apenas por si, deixa de existir, do mesmo modo que o universal precisa das suas partes para subsistir. Por isto, esta relação nunca é estática, fixa, mas sim uma relação de movimento, um movimento que é, para Hegel, dialético.

\footnotetext{
20 "die konkrete Freiheit aber besteht darin, daß die persönliche Einzelheit und deren besondere Interessen sowohl ihre vollständige Entwicklung und die Anerkennung ihres Rechts für sich (im Systeme der Familie und der bürgerlichen Gesellschaft) haben, als sie durch sich selbst in das Interesse des Allgemeinen teils übergehen, teils mit Wissen und Willen dasselbe und zwar als ihren eigenen substantiellen Geist anerkennen und für dasselbe als ihren Endzweck tätig sind, so daß weder das Allgemeine ohne das besondere Interesse, Wissen und Wollen gelte und vollbracht werde, noch daß die Individuen bloß für das letztere als Privatpersonen leben und nicht zugleich in und für das Allgemeine wollen und eine dieses Zwecks bewußte Wirksamkeit haben.” (HEGEL, 1970b, § 260, pp.406-407).
} 
O Estado como manifestação da Razão é necessário, representando uma necessidade absoluta, que é uma necessidade lógica da razão. Todo o sistema hegeliano se encaixa: liberdade e necessidade estão ligadas, porque se é livre pela mediação da razão e esta comporta uma certa necessidade, sendo-se livre pela compreensão da necessidade.

Só no Estado se é livre plenamente: o Estado é manifestação da liberdade, que se manifesta mediada pela razão, porque a liberdade é o exercício da racionalidade, e, por isso, o Estado é, igualmente, concretização efetiva da razão, e a necessidade é aquilo que, por tal racionalidade, é compreendido. A razão compreende o universal como necessário de realização. O Estado é essa totalidade que precisa de ser efetivada.

\section{Nótulas finais}

Como referido à guisa introdutória, não quisemos fazer aqui qualquer apologia das teses hegelianas, ao invés, como anunciado, procurámos contribuir para o debate em torno de uma certa noção de Estado e de uma certa relação com o indivíduo que a acompanha nos Princípios da Filosofia do Direito de Hegel.

Porquanto estamos convictos de que não devemos ir para lado algum sem saber muito bem de onde viemos. Por isso, não ignorando as considerações de Hannah Arendt em As Origens do Totalitarismo (Elemente und Ursprünge totaler Herrschaft, 1951) num tom acusatório de uma "visão totalitarista” em Hegel (cf. ARENDT, 1979, p.249), porém, crendo-as abusivas, devemos procurar compreender que tipo de papel compete ao indivíduo dentro de uma "totalidade de relações", numa relação dialética entre Estado e indivíduo (onde o Estado é a totalidade relacional da vida dos indivíduos, sem procurar eliminar a própria individualidade), em vez de uma relação Estado-indivíduo (onde o indivíduo se dissolve no Estado).

Neste encalce, ao contrário das teses defendidas por Francis Fukuyama no seu O Fim Da História e o Último Homem (The End of History and the Last Man, 1992) (cf. FUKUYAMA, 1992, p.xii), precisamente inspiradas em Hegel pela parte que toca a este quanto à doutrina (acabada), defendendo o "final da história" no Estado prussiano e aquele nos demoliberalismos, entendemos, também num certo sentido hegeliano, mas quanto ao seu modo de pensar (dialético), que o "final da história" a vir alguma vez a existir não será tão cedo, nem enquanto houver possibilidade de desenvolvimento social e natural. 
Em suma, cabe procurar pensar que tipo de Estado(s) está o ser humano a herdar e a edificar, que tipo de papel compete ao indivíduo dentro de uma "totalidade de relações" e que tipo de mediações assomam como necessárias, sem cair em discursos de tipo marcadamente determinista e onde podem, e até onde, podem realmente os indivíduos concretizar.

\section{Referências}

ARENDT, Hannah. The Origins of Totalitarianism. San Diego-New York-London: Harcourt Brace \& Company, 1979.

ARISTÓTELES. Política. Trad.: António C. Amaral e Carlos de C. Gomes. Lisboa: Veja, 1998.

BARATA-MOURA, José. A «Realização da Razão» - um programa hegeliano?. Lisboa: Caminho, 1990.

FERREIRA, Manuel J. Carmo. Apresentação. In: HEGEL, Georg W. F. Prefácios. Tradução, introdução e notas: Manuel J. Carmo Ferreira. Lisboa: Imprensa Nacional Casa da Moeda, 1990.

FUKUYAMA, Francis. The End of History and the Last Man. NewYork: McMillan, 1992.

HABERMAS, Jürgen. The European Nation-state - Its Achievements and Its Limits. On the Past and Future of Sovereignty and Citizenship. In: BALAKRISHNAN, Gopal (Ed.). Mapping the Nation. London-New York: Verso, 1999, pp.281-294.

HEGEL, Georg W. F. Enciclopédia das Ciências Filosóficas em Epítome. Vol. III. Tradução: Artur Morão. Lisboa: Edições 70, 1992.

HEGEL, Georg W. F. Enzyklopädie der philosophischen Wissenschaften im Grundrisse. 1830. Dritter Teil. Die Philosophie des Geistes. Mit den mündlichen Zusätzen. In: HEGEL, Georg W. F. Werke in 20 Bänden (Doravante: Werke.). Vol.10. Frankfurt a.M.: Suhrkamp Verlag 1970a.

HEGEL, Georg W. F. Grundlinien der Philosophie des Rechts oder Naturrecht und Staatswissenschafl im Grundrisse. Mit Hegels eigenhändigen Notizen und den mündlichen Zusätzen. Werke. Vol.7. Frankfurt an Main: Suhrkamp Verlag, 1970b.

HEGEL, Georg W. F. Phänomenologie des Geistes. Werke. Vol. 3. Frankfurt an Main: Suhrkamp Verlag, 1970c.

HEGEL, Georg W. F. Princípios da Filosofia do Direito. Tradução: Orlando Vitorino. São Paulo: Martins Fontes, 1997.

WAHL, Jean. As Filosofias da Existência. Tradução: I. Lobato e A. Torres. Lisboa: Publicações Europa-América, 1962.

WEIL, Eric. Hegel et l'État. Paris: Vrin, 1950. 